\title{
EL OJO HEREJE DE NIKOS KAZANTZAKIS
}

\section{Roberto Quiroz Pizarro \\ Universidad de Chile, Chile}

Resumen: En N. Kazantzakis la religión tuvo una gran preocupación personal y literaria. Varias de sus obras pasan por el tema de la fe. Sin embargo, para Kazantzakis la fe religiosa se constituye en un problema filosófico. Quizá en su obra hay varias respuestas para el mismo y gran problema.

Palabras clave: Kazantzakis, religión, Comedia, Dios.

\section{THE HERETIC EYE OF NIKOS KAZANTZAKIS}

Abstract: In N. Kazantzakis the religion had a great personal and literary concern. Several of his works go through the theme of faith. However, for Kazantzakis religious faith constitutes a philosophical problem. Perhaps in his work there are several answers for the same and big problem.

Keywords: Kazantzakis, religion, Comedy, God.

Recibido: 20.09.2017 - Aceptado: 20.12.2017

Correspondencia: Roberto Quiroz Pizarro

Email: alfanamaste@hotmail.com

Lic. / Mag. Filosofía-Universidad de Chile.

Doctor (c) Universidad de Chile - (c) Universitat Jaume I-Valencia 
Al sonido de una sola palabra, "madre",

indicios terrestres que llenan el vacio humano

En su momento tanto se habló del afán nihilista y agonizante de la filosofía de Nietzsche, de su ateísmo militante y auto satisfactorio, del antihumanismo y antisocratismo por principio, que no cabía interpretar a este filósofo más que como un monstruo para la cultura de Occidente. Si había una pesadilla en el mundo occidental, esa se llamaba Así habló Zaratustra o El crepúsculo de los ídolos o Más allá del bien y del mal. Se tiene la sospecha que un trato semejante se le dio al escritor cretense por parte de las voces de la autoridad en Grecia, y que intelectuales nacionales y el mundo religioso en general no supieron cómo interpretar a este nuevo Nietzsche de la literatura neogriega. No fue un hecho menor que la propia Iglesia Ortodoxa y facciones políticas tomaran la obra de Kazantzakis como una cuestión personal, en donde el pensamiento temerario no era bien recibido allí, porque un individuo se atrevía a cuestionar o transgredir las formas canónicas del establishment. Por eso, regresando a los comienzos literarios de Kazantzakis uno va ampliando la mirada de lo que posteriormente fue motivo de escándalo entre la masa que no vio toda la multitud de voces que existía en un mismo escritor.

\section{Abismo y fe, una dialéctica temprana en Kazantzakis ${ }^{1}$}

Sabemos a través de su vasta obra que Kazantzakis fue un intelectual que no tuvo prejuicios de una exclusión entre Oriente y Occidente. Antes por el contrario, se nos dice que "en efecto, el pensamiento de Kazantzakis es básicamente una composición de bergsonismo, nietzscheismo, pragmatismo, vitalismo, bizantinismo, budismo y un cristianismo sui generis" ${ }^{2}$. Sin embargo, esta primera calificación dada a su corpus por algunos críticos nos pone también en una perspectiva de la visión final que

1 El siguiente escrito pertenece a un material de elaboraciones adscritas a un programa de estudios doctorales bajo un régimen de interrupción. El tema acordonante ha sido la exploración del pensamiento kazantzakiano en sus proyecciones ideológicas y filosóficas. Se deja constancia de que se trata de un escrito abierto, en desarrollo, perfectible y modificable en su punto final.

2 A. Boyunga, "Mithos ke paravolí sto ergo tu Niku Kazantzaki”, revista Diavazo, Atenas, $n^{\circ} 377,1977$, p. 82. 
de Kazantzakis habría que tener, un escritor de lo espiritual y filosófico sin fronteras.

En tal sentido, esa cercanía de lo oriental y occidental cuyos iconos a grosso modo son lo místico y filosófico en Kazantzakis, estructuran en sus obras una amplitud ideológica que encierra caminos absurdos y complejos en el delineamiento de su pensamiento siempre en movimiento y siempre en mutación de ideas y aporías. Uno de esos ejercicios en que el intelectual y el hombre de fe sortean visiones contrapuestas puede apreciarse en una temprana obra de su repertorio teatral. Pensamos en Comedia ${ }^{3}$ como hilo conductual y uno de esos puntos paradigmáticos que nos permiten situarnos dentro de una crítica explícita a la religión y a sus discursos paralelos que nos llevan a instaurar una visión filosófico-terapéutica de las creencias como una posible salida: ir de las ruinas de la fe cristiana occidental hacia una posibilidad de reencuentro con otro discurso, el lenguaje de la fe laberíntica, compleja y negativista, oculta a la razón, en donde la petición de logos y argumentaciones se ha de hundir en una renuncia de respuestas más acorde al tipo budista. Lo inefable, por así decirlo, no está como privilegio de alguna tradición, ni occidental ni oriental, sino que parece un fenómenos sin coordenadas dominantes.

3 En efecto, esta obra teatral de Comedia como El Maestro Primero y otras que conectan ideas semejantes de un período cercano, anuncian una sensibilidad trágica y un espíritu helénico muy contrapuesto al cristianismo posterior. Nociones de culpa, responsabilidad, justicia, libertad, destino, sentido de la vida, imagen de lo divino, esperanza, contingencia, irrumpen con un dramatismo cosmológico en que el hombre está aún lleno de preguntas, interrogantes y miedos ancestrales. Esta pieza poco conocida en comparación a sus grandes novelas posteriores se mueve como un mecanismo que pondrá a máxima tensión lo que son aspectos tan humanos como la fe y la esperanza, la racionalidad de las certidumbres y los nihilismos, la confianza de un sentido y la fatalidad de la nada. La seducción de obra literaria explota en su tesis de planteamientos, en la organicidad de los contrapuntos que al autor le interesa poner a la vista, plantear las problemáticas ante todo y no dar una respuesta fácil. En este caso Comedia, una obra de experimentación filosófico-espiritual será como el encuadre gestáltico analítico para abrir terreno en el corpus ideológico-filosófico del autor griego y mostrar los conflictos explícitos que nos plantea esta obra, todo lo cual tendrá ecos lejanos en la opinión y valoración sumaria de los críticos respecto a la figura de Nikos Kazantzakis. 
Una de las primeras enseñanzas que nos deja esta obra corrosiva es que la sintamos como un grito de libertad y un abandono de las subyugaciones sociales y de las ortodoxias. La proeza de Kazantzakis ha sido intentar asumir el postulado de que la persona, el individuo es prioritario y está por encima de las verdades reverenciales y reveladas o instituidas por la iglesia, por el culto o la sociedad ideologizada, por el grupo dominante. En toda la obra del escritor cretense se enfatiza en forma creciente el hecho de que la libertad real no está conectada necesariamente con los sistemas doctrinarios, ni con la tradición o con una postura logocéntrica o de megarrelatos, tal como la ostenta la fe cristiana en esta obra, o el discurso de la ciencia o de la modernidad filosófica. Aun y más que eso, Kazantzakis nos lleva a lucubrar que la libertad del alma es lo que últimamente importa. Es decir, que se trata de una libertad que nos libera hasta cuando estamos externamente sujetos a la tiranía existencial del mundo. Quizás desde este punto de vista, una obra como Comedia, siendo una obra temprana, primeriza, nos sirve de punto de observatorio para demarcar lo que posteriormente va a ser en Kazantzakis una especie de largo recorrido ideológico en su personal ascesis de liberación.

Este grito desesperado nos despierta y dice: que las instancias de la vida humana dejen de ser tan a la medida de nuestros propios prejuicios, obsesiones, pequeñeces, miedos, intereses, egoísmos, visionismos. La cotidianeidad de aquellos personajes encerrados en esa obra del teatro negro de Kazantzakis, de Comedia, la sensibilidad que los mortifica en un solo cuadro de acción universal, no necesita de un ángel protector que los salve; más bien es preferible que el espíritu de verdaderos hombres descienda a los abismos de la nada antes que permanecer en las ilusiones o en las sombras del fetichismo religioso. Sin embargo, tales motivos, como la espera y el temor religioso, la agonía y la muerte, el infierno y el paraíso, constituyen pendientes, obstáculos a remontar: ellas están presentes para que se las remonte; están hechas para que se las conquiste a cualquier esfuerzo. Es lo que propondrá Kazantzakis a su manera.

En Comedia, la fe, la religiosidad, cuyo dogma central estará escenificado en el paso de la vida a la muerte y en su promesa de castigo y recompensa en el paraíso, es tratada con tonalidades patéticas y crueles. Esa mayoritaria visión cristiana de fondo, defendida a ultranza por el protagonista central de la pieza, el todopoderoso Asceta ${ }^{4}$, acabará siendo un

4 El Asceta es uno de los personajes centrales de la obra, y dentro de lo llamativo 
carnaval de agonías y aporías extremas, en lo cual inocentes, hambrientos de santidad, ignorantes, vividores, no creyentes y hasta pecadores, todos por igual, descubrirán que la espera --materializada en la obra misma en esa misteriosa sala con velas que se apagan progresivamente-- se convierte en una burla demagógica, una falsa conciencia de la que es costoso substraerse. Como se sabe para llegar a desconfiar de la religión, Kazantzakis había tenido por maestro a un filósofo llamado Nietzsche. Las escenas de Comedia serán un potente corrosivo para la fe dogmática tan criticada por el filósofo alemán: "Dios ha muerto", "el sentido de la tierra", "después del caos viene la serenidad", "más allá del bien y del mal", "la inocencia del devenir", "la superhumanidad", los “espíritus libres", serán algunas de las resonancias y consignas del grito nietzscheico en Kazantzakis con el que procuraba levantar el espíritu del hombre. Asimismo, fiel discípulo de Nietzsche en la primera década del siglo, Kazantzakis continuará la sospecha ante los dictámenes del logos eclesiástico, el cual, por tradición, acentúa los elementos de una fe que para ser virtuosa no debe perder de vista la esperanza, el temor, la obediencia, los límites de la conducta y el pecado. Hasta las últimas consecuencias Kazantzakis reflexiona sobre qué puede esconderse detrás de la esperanza y el temor religiosos. Interroga si acaso la espera de algo es a la vez una invitación para el avance del temor. Observa que en este esquema, cuando existe esperanza -- esperanza teológica-escatológica en los personajes de Comedia-- también existe espacio para el temor y la vacilación ${ }^{5}$. De manera que el que espera está ya

e ideológico de la propuesta crítico experimental de lo teatral de esta obra, es que Kazantzakis pone a doce personajes que no tienen un nombre de acuerdo al sentido literario de la dramaturgia, sino que sus apelativos son abstractos y universalistas, casi como reducidos a una función social. Así otros que comparecen en la puesta en escena son el Obrero, la Madre, la Niña, la Monja, el Necio, La Joven, El Joven, etc.

5 Interesante es la tesis dualista de estos contrastes de amor-odio, esperanzatemor, que ha guiado a los discursos predicativos de las religiones en general. Disciplinas como la sociología, antropología, etnografía, psicobiología y el caso puntual de Nietzsche en la filosofía, han reflotado el fondo irracional que juegan el temor y la inseguridad humana más allá de lo que se le reconoce, pues así facetas como la esperanza, añoranza, promesa o certeza que profesan las religiones en general, acaban potenciando el lado perverso de sus adeptos, pues se alude a estratos de la naturaleza humana no controlados o reprimidos a la fuerza. Esperar algo de modo dogmatizante detona frustración, una fe sin 
predispuesto para el temor y, a su vez, el que teme algo es porque también espera algo. Entonces, la esperanza conlleva inevitablemente al temor, a la angustia existencia, y éstos presuponen la esperanza sin certezas. Esperanza y temor marchan y coexisten paralelamente en la religión, en los discursos que han anticipado una respuesta universalista.

¿Qué sucede en el logos cristiano? La ordenación de estos elementos parece estar oculta, puesto que cuando se enciende la luz del ágape, se pretende excluir a toda costa la presencia del temor y, al mismo tiempo, afirmar que el que ama sólo tiene esperanza. Entonces, dado que la caritas cristiana espera y puesto que el temor coparticipa de la esperanza, de ello, entonces, resulta que el temor sí tiene cabida en el ágape religioso. Sin embargo, en la perspectiva de la Iglesia todo esto se encubre: la predicación de siempre es que el amor no presupone el temor y que éste no tiene espacio en la esperanza. Pero todo esto no es más que un engaño dentro del credo religioso y Comedia será el espectáculo fatal que denunciará esta terrible sospecha, de reconocida herencia nietzscheica.

\section{Un camino de liberación, la lejanía divina}

Dentro de su sensibilidad espiritual lo que le parece más desmesurado a Kazantzakis es el paradigma de una soteriología de privilegios antropomórficos y de una cristianización a través del logos --la palabra dicha y oída--, y, en consecuencia, del montaje de aquella parafernalia de interdictos morales, metafísicos, escatológicos y religiosos que no hacen de la fe sino un códice muerto o un formulario más, restándole misterio y abismo al estado mismo de la existencia humana.

El panorama de la fe debe cambiar y Comedia es un primer ensayo. El trasfondo crítico de esta obra es rotundo pues su movimiento virtual de sólo media hora ${ }^{6}$ logrará resquebrajar el "círculo infernal" de la

límites lleva al descontrol, pues cualquier imprevisto de esa fe esperanza puede conllevar ese letal "efecto mariposa". Un amigo y lector alemán de Kazantzakis, Kerenyi, comenta que las Iglesias hacen comedia al prometer tanto a sus fieles, lo cual acaba en una peor tragedia para los humanos que han creído.

6 Kazantzakis deja claras indicaciones intracontextuales de que la obra tiene un movimiento dramático de media hora, de que todo se consuma en esa cápsula mensurable que a la vez muestra una especie de paralelismo entre lo que sería el tiempo propiamente interno de la obra y lo que pasa a ser su montaje como tal en las tablas. 
ley, la culpabilidad, el pecado, el castigo, la mala conciencia. El derrumbe comienza con su protagonista central: el Asceta, a quien le sobreviene un ataque de dramatismo babélico cual estigma de Caín, se irá consumiendo de resentimientos y de una locura de hereje. Es como si la pugna entre lo dogmático y la fe pura ocurriera dentro del mismo Asceta. Su conciencia participa del alfa y omega, del dominio y extinción del dios doctrinal y providencial, de la fe idolátrica y cosificadora, del logos manipulador y totalizante.

En Comedia nada de silogismos o pruebas de revelación que suplanten la poesía divina del abismo. En el fondo, se trata de una sensibilidad para lo místico. Kazantzakis ha querido que el vértigo de esta obra ateísta y negadora nos abandone justo delante del abismo. Quizá para preparar al hombre ante una lucidez del abismo. Entonces, no queda más remedio que sentirnos perdidamente moribundos o más bien disponernos con fuerzas para una ascesis liberadora, pero eso sí, ahora solos y $\sin$ muletas ideológicas.

Dentro de la antesala oscura de Comedia, y también fuera de ella, todos andamos a tientas con nuestra fe, y no precisamente por "mala fe", sino por una extraña pequeñez y pesadez de espíritu. Los personajes de la representación "no saben lo que hacen" y precisamente así muestran la debilidad de su supuesta fe en el instante crucial de cuando el rostro divino se les manifiesta como abismo y silencio. Será que, como el Asceta, nosotros también buscamos lo sagrado con intereses y nos enceguecemos con expectativas de predominio cuando abusamos del deseo de querer saberlo todo o de manipularlo siempre a nuestra medida. Sin embargo, las coordenadas perceptuales de nuestro narcisismo religioso se tornan difusas, densas como la oscuridad de Comedia, cuando la otredad divina parece habitar en lejanos horizontes o simplemente cuando no escucha el llanto humano, las demandas piadosas. Kazantzakis muy bien lo sabía: en nuestra pomposa fe padecemos de una debilidad crónica que no resiste puertas cerradas y estrechas, ni silencios y penumbras divinas. Por el contrario, queremos a un Dios que siempre esté ahí, delante, clavado sobre un muro exterior y a suficiente distancia de nuestra conciencia para que nos escuche.

La figura paradigmática del Asceta marcará la intensidad tonal de una fe atrapada fatalmente en sus dogmas y obsesiones de todo tipo. Cuando los acontecimientos no responden a esas expectativas humanas, sobreviene el caos, todo en el Asceta se volverá vaguedad y turbación 
de reclamos. $\mathrm{Su}$ fe está modelada por arena reblandecida que no soporta tempestades de oscuridad y silencios. A medida que avanza Comedia y toma la palabra el Asceta, vemos que sus expresiones de prepotencia ideológica y juego de rebeldías blasfemantes no serán suficientes como para alterar la vastedad divina, imagen de un Dios que deja una cortina de sombras sobre la agitación humana.

Las sucesivas escenas acentuarán un deseo paradojal: los personajes cautivos esperan una señal positiva respecto de la promesa divina de salvación. Inclusive, esperan un rayo, algo del más allá que los asesine, pero que algo ocurra. En una palabra, lo que les interesa es que lo trascendente se ajuste textualmente a lo que la fe les ha enseñado. Es más, buscan a ese Dios como quien requiere de un negociante que les vende la vida eterna. Sin embargo, las puertas del enigma no se moverán un ápice ante la demanda obsesiva y dogmática de un credo totalizante que reduce lo celestial a casilleros humanos. En tal sentido, tanto la sumisión ciega como la protesta luciferina del Asceta, de gradual estallido hacia el final de la obra, conducen a éste a perder de vista la "experiencia apofática" de la oscuridad trascendente y con ello, a dejar de ser consciente de la provisionalidad y limitación de tales concepciones?

7 La milenaria idea de Dios o de lo divino es una manifestación itinerante, una fenomenología proteica, historia y acontecimiento de un misterio. Habría conciencia de una asimetría entre lo que sea la idea humana o acto racional que se tiene acerca de Dios y lo q sea ese Dios mismo. Convergen así diferentes elementos o posiciones: "pathos de la distancia", "vía negativa" filosóficoteológica, "otredad de lo Absoluto", "deus absconditus", "abismo divino", "lo inefable" o la "vacuidad oriental". Si al comienzo hubo un optimismo teórico sin restricciones, poco a poco se comienza a pensar con más autocrítica y desconfianza antropológica, y se volatiza esa vieja idea de un Dios o ser supremo. Por cierto, una idea tal que se había enriquecido por siglos y tradiciones empieza a aumentar sus coeficientes de incertidumbre y desborda su lozanía primera. En el occidente este fenómeno partiría unos siglos después de Cristo, dejando ecos en el llamado neoplatonismo pagano, en el cristianismo primitivo de la apologética y patrística, en los sincretismos, las herejías, los orientalismos y en Plotino, quien por lo demás desarrollará una interesante dialéctica entre platonismo y aristotelismo. Gracias a Plotino hay un cuestionamiento filosófico a las imágenes y conceptos que las tradiciones religiosas en general hacen del Uno-Dios-divino: «un ser tiene, por así decirlo, la forma del ser. Pero él (Uno) está exento de toda forma, incluso inteligible. La naturaleza del Uno es generadora de todas las cosas, y por ello no puede ser ninguna de ellas. No es, 
El drama de la fe que sacude a Comedia quizás no sea más que la plena noche apocalíptica del espíritu. Puede ocurrir que, desde tal punto crítico, vislumbremos los espacios mínimos para una vía negativa y existencial del "nous patheticós", esa experiencia de abismo y lucidez que nos ilumine mediante una "fe trágica", sobrehumana. Por otro lado, parece claro que con la figura del Asceta estamos situados a las puertas del laberinto de una fe tradicional, impura, desgastada, intervenida por deseos y ansias de seguridad. Sin embargo, en las escenas de Comedia vemos una dimensión de contraste con el logos del Asceta. A este personaje le hace falta silencio interior, una disposición que lo haga capaz, aún en el bullicio y la agitación exteriores, de sentir e irradiar serenidad. A medida que las tinieblas y la nada de la sala circundan al símbolo de la fe muerta en el Asceta que exige cuentas a lo divino, nos percatamos de que su fe manifiesta demasiado ruido de expectativas y proyecciones. En este terreno, la teología negativa es la expresión mística que mejor muestra la vivencia existencial delante del abismo divino. La paradoja de la proximidad con el "rostro sin rostro" de lo sagrado, predispone al místico en gran medida a vivir la nada, el vacío dentro de sí, fundamentalmente. Establecer unos parámetros objetivos, científicos, es ya idolatrizar, medir lo inmedible o no reconocer el homo mensura del protagorismo, el que nos disuade de proyecciones absolutistas. Por antonomasia, Dios no es nada de lo que discriminan nuestras pupilas ingenuamente videntes o

pues, un algo,ni una cualidad, ni una cantidad, ni intelecto, ni alma. Tampoco está ni en movimiento ni en reposo, ni en un lugar, ni en un tiempo. Es lo que es en sí en la unidad de su esencia, o, más bien, sin esencia, siendo anterior a toda esencia, al movimiento y al reposo. Estos son, en efecto, accidentes del ser, que lo hacen múltiple" (VI, 9, 3). Se especula entonces, que ante el "horror vacui" es que las tradiciones juegan con artilugios de fe e intelecto a "cazar a Dios en sus redes". Ante ese misterio de lo divino caben dos vías, la vía afirmativakatafática o la vía negativa-apofática. Esa teología bizantina negativa ilustra su camino oscuro con fragmentos bíblicos como «No podrás ver mi cara, porque quien la ve no sigue vivo" (Éxodo, 33); o donde se dice de Dios que «es el único que posee la inmortalidad y habita una luz inaccesible, a quien ningún hombre ha visto ni puede ver" (1 Tim 6,16). En una misma tradición religiosa o mística como bíblica hay rasgos de ese doble camino afirmativo y negativo. La pregunta de fondo sigue siendo ¿qué podemos conocer de Dios?, y autores como Kazantzakis toman en cuenta respuestas de toda índole, afirmativa y negativa, siendo Comedia, en este sentido una vía apofática. 
conceptuales, nada representacional, objetivo. Esta vía negativa conlleva cierta prudencia antropológica al aconsejar la disposición a la suspensión del juicio, al retiro de las valoraciones, a la moderación de las proyecciones y categorías teológicas. Es desechar las experiencias de segunda mano, y dejar al individuo libre de creencias y dogmas que no lo ayudan a madurar.

\section{El camino oscuro de otra fe}

A través de esta empeñosa ascesis de decir "Dios no es esto", se revela la sobreabundancia y multiformidad de los horizontes prepersonales del ser absoluto. En efecto, los místicos de Oriente y Occidente reiteran que la divinidad nos sacó de la nada porque quiso hacernos semejantes a ella: la nada de Dios, ese silencio creador es fundamento sin fundamento que opera -aún en nosotros-- sin que haya nada más allá de sí mismo. Es la aseidad divina, cuyo resplandor es abismo para el hombre. Aquí, Comedia es su dramático corolario. Además, la obsesión por un Dios totalmente conocido, predecible --caso extremo del Asceta--, más bien revela una disposición defensiva, temerosa y no de un natural respeto ante lo que como realidad trascendente es cualitativamente Otro, un abismo de horizontes abiertos. De modo que, de ahora en adelante, el logos del Asceta ya no estará solo en escena, pues ante él se yergue la multioscuridad del deus absconditus de Comedia.

El "dios escondido" de la teología negativa tiene que ver con el asombro, la incertidumbre vital, la sorpresa, el misterio esencial, el abismo. Mediante el asombro se nos presentan esenciales interrogantes: ¿qué es esto?, ¿de dónde proviene?, ¿qué relación tiene conmigo?, ¿qué consecuencias puede traer?

A través de ellas, el hombre se sitúa frente a lo que no es él, tal como en Comedia se nos aparece el abismo del silencio, de la nada misma. Entonces, colocado frente al hecho o delante del prójimo, quien se siente interpelado por el asombro se retira a una especie de segundo plano; se borra a sí mismo en cuanto es sólo la "otredad" de su estupor lo que se le muestra como digno de ser admirado, sentido, contemplado, vivenciado. Vemos que en la situación límite de Comedia, no se alcanza ese respeto último ante lo desconocido del abismo divino o numinoso. Al contrario, tenemos a la vista la figura del Asceta que, enceguecido de dogmas, se arroja a sí mismo la perspectiva de Dios, e, incluso, sin dudarlo siquiera, apenas llega a la sala de espera, no hará más que pontificar sus verdades, aferrarse a una cierta tejedura de argumentos teologales. 
En atención a las impresiones que nos sugiere Comedia, sentimos la tentación de creer que esta perspectiva del Dios mudo, lejano, tiene a partir de aquí una de sus primeras manifestaciones dentro del corpus kazantzakiano. La conjunción del dios escondido y del silencio místico parece permitirle ensayar posibilidades de una fe trágica, eso sí, pasando previamente por el despojamiento de las proyecciones y prejuicios del dogma tradicional. En todo caso, la temprana Comedia, a la vez que representaría una visión crítica de la creencia religiosa, también posee una especial virtud filosófica: albergar el nuevo mito que nos ha de conducir a "comer del árbol del silencio", puesto que el dios de Kazantzakis sostiene un rostro de silencio inconmensurable. A propósito de esto, recordemos que esa doctrina del silencio tendrá con posterioridad dos momentos culminantes en el pensamiento del escritor griego: en Ascesis ${ }^{8}$, cuyo subtitulo "Salvatores Dei" tiene mucho que decir, se señala que la quinta etapa preparatoria del camino espiritual considera precisamente $E l$ Silencio, silencio en su aspecto parametral como el fin de todo esfuerzo y combate. Unos fragmentos de Kazantzakis darán una idea de tal camino:

"13. Este último grado de la ascesis se denomina Silencio. No porque su contenido sea la suprema desesperación indecible o la suprema alegría o la esperanza indecible. No porque sea el supremo conocimiento que no se digna hablar o la suprema ignorancia que no puede.

14. Silencio significa: cada uno, cuando ha terminado de servir en todos los trabajos, llega a la más alta cima del esfuerzo. Más allá de todos los trabajos él no lucha ya, no grita ya, madura del todo, silenciosamente, indestructiblemente, con el Universo",

8 N. Kazantzakis: Ascesis Salvatores Dei. Introducción Aziz Izzet, Traducción Enrique de Obregón. "El silencio", p. 1024.

9 Ibídem, loc. cit. 
Asimismo, la presencia del silencio en la Odisea ${ }^{10}$ asumirá la dimensión de ser más bien una respuesta fronteriza ante quienes van en búsqueda de un más allá escatológico o de los que esperan la suprema consolación o la suprema condenación. En otra obra de teatro, el Teseo ${ }^{I l}$, Kazantzakis nuevamente le concederá a su Dios el don de la palabra desde el silencio.

El holocausto desatado al interior de Comedia debiera ayudar siquiera a vislumbrar la sombra de Dios, la huella de su silencio: "cuando la oscuridad es total, se pueden ver las estrellas", dicen los místicos. A la vez que es un abismo, también muy adentro de esta obra palpita aquella otra fe que merecería sobrevivir al diluvio. ¿De qué o de cuál fe se trataría?

"Sería una fe que se hunde en las tinieblas, en una nueva 'noche del entendimiento'... ante un Dios que ya no poseería los atributos de la 'providencia'; un Dios que no me protegería, sino que me entregaría a los peligros de una vida digna de ser llamada humana... Lo que significa noche para el entendimiento significa también noche tanto para el deseo como para el temor, noche para la nostalgia de un padre que me proteja. Más allá de esta noche, y solamente más allá, podrá recuperarse el verdadero significado del Dios que consuela".

Sería una fe trágica en su más hondo sentido, en la cual la Luz de la fe estaría más allá de toda magnitud humana, más allá del logos, para entenebrecerse en su abismo místico. Sería una fe que acepta la voz del silencio, la ausencia de expectativas y el pathos de la lejanía. Hablamos de fe trágica pero no precisamente debido a que la veamos viva en alguno de los personajes de Comedia. Antes, al contrario, entre ellos reina la desesperación religiosa tradicional, la inseguridad y el exceso de dogmas. Sin embargo, lo que aquí percibimos de fe trágica es la interpretación de una perspectiva de un Dios escondido en las sílabas de la nada, un Dios lejano, mudo, ausente, silencioso, abisal, y que, lisa y llanamente, no se somete a los intereses y cálculos del hombre. No todos los personajes

10 N. Kazantzakis: Odisea. Traducción M. Castillo Didier.

11 N. Kazantzakis: Teseo. Traducción Enrique de Juan. 
imploran con esa fe intervenida de consuelos y exigencias, prototipo del Asceta, pero la mayoría sí que no alcanza a tener una metanoia, un cambio de fe, y asumir desde el abismo una eudaimonía o disposición interior que les haga capaces de entrar en la nada.

Imposible no pensar en la fe sapiencial de los profetas, quienes desde una semioscuridad del espíritu despierto, renacían hacia una fe serena, sin yugos y aceptadora del abismo místico. Encontramos la ejemplificación de esto en Job, cuya fe trágica ante lo sagrado no le permitía dilapidar su alma en razonamientos o recompensas, en diatribas o resquemores. En medio de la sala infernal que rodea al Asceta en Comedia, en verdad muy otro sería el testimonio vital de este profeta bíblico frente al abismo del silencio: "nada me ha dicho, pero lo acepto todo". Su serena fe nos hace pensar en una conciencia volcada más allá del beneficio personal y del triunfalismo religioso, tan fuertemente estampado en el Asceta.

De acuerdo a esto, en la figura del antiguo profeta se establece una violenta oposición entre la verdadera fe en Dios y esa ley de retribución retratada en el protagonista de Comedia. Mientras que la fe trágica de un Job está más allá de toda evidencia, certidumbre, lógica humana, notamos que la fe impura del Asceta es una fe más bien intervenida por el yo engañador, que siempre exige respuestas, dogmas, garantías, consuelos.

Comedia nos enseñará que quizá nosotros, en lugar de correr tras las evidencias, seguridades o intereses, lo que sí deberíamos hacer es buscar el abismo y el silencio de la infinitud. Pero, ¿cómo siquiera presentir el umbral místico de un Job? Quizás su voz eterna nos diga: "ver como si no se viera; oír como si no se oyera; sentir como si no se sintiera; poseer como si no se tuviera".

Así vista de cerca, sospechamos que la Comedia de Kazantzakis parece una especie de meditación desesperada, última, pero animada por la pulcritud de un severo ejercicio espiritual, que nos acosa y nos desenmascara la fe impura del Asceta. Una fe contaminada por una rígida conciencia entronizada siempre en su "punto de vista" humano. En diferentes grados, relieves, niveles de significado, esta representación de los doce --concuerda con el número de personajes--, apóstoles de la agonía que nos muestra Comedia es la historia del hombre encerrado en su caparazón existencial, credo, o ideología; es la parábola del hombre endurecido en su conciencia condicionada, que lo sujeta a lo conseguido en el mundo de las apariencias-sombras, y que sufre por todo cambio. 


\section{Abismo y fe existencial agonal}

En Comedia nos hemos referido a la presencia del "abismo". Detengámonos brevemente en ello. Considerando su etimología griega, "abismo", 'abyssos', literalmente significa "sin fondo". El vocablo "byssos", nudo central del significado, se refería originalmente al fondo o piso del océano. Asimismo, la palabra "abyssos" aparece en el libro del Apocalipsis, donde su dimensión semántica también indica lo opuesto al "paraíso", esto es, el infierno. Precisamente, en Comedia, uno de los antiprofetismos esbozados es que el paraíso cristiano no existe. En su lugar, nos encontramos con el abismo, con la nada, el absurdo y el silencio de Dios. Pero finalmente tampoco se trata de un infierno simplemente religioso o ético: es el abismo de lo sobrehumano que con su claroscuridad extingue el sentido humano.

El hombre no tiene solamente hambre de lo absoluto por causa de sus proyecciones, sino que es interiormente sensible. En el espacio de la fe, Dios es la proyección de lo absoluto, inmersa de forma permanente en el espíritu universal.

Uno es un abismo, una profundidad paralela y originada por el otro abismo, la otra profundidad: abyssus abyssum invocat. La vía negativa de la fe mística participa del misterio divino, partiendo desde la sencillez y la prudencia misma de la existencia humana: el hombre no supera nada; el misterio lo supera a él. Por consiguiente, el Adoro Te, latens deitas, Te adoro, deidad desconocida, no es "lírica especulativa" para él, sino el principio de su sentir metafísico. Este hombre de la fe mística vivirá, con todo su ser, en el secreto del abismo.

Ante la absurdidad radical de lo que pasa en Comedia, ¿qué hacer?

"El hombre errante que grita en el abismo supera el abismo. Su mismo grito lo levanta por encima del abismo".

En el caso del Asceta, lo vemos hasta el último momento deambular a grito herido. Pero nada cambia; las puertas no se abren; están cerradas como lápida fría. Aunque el Asceta desgarró su espíritu en gritos de blasfemia, olvidó que Dios es a la vez luz y oscuridad. 
"Dios es luz; en él no hay oscuridad" - dice el apóstol Juan.

"Eres verdaderamente un Dios oculto" - dice el profeta Isaías.

¿A dónde se fue la lógica humana?

Cabe la fe humana en la palma de la mano, es lo que de muy en el fondo va proponiendo Kazantzakis con sus lucubramientos literarios.

Hay una oscuridad que proviene de un exceso de luz, por rebasamiento como cuando queremos mirar al sol; hay al mismo tiempo una oscuridad que significa tinieblas. La intensidad de Dios nos produce oscuridad. Tal es la huella del Deus absconditus; y por eso, delante de su Ser/Nada hay siempre un velo, una cortina, un abismo como el de Comedia. El Asceta de la obra y en general, los hombres, hablan tanto y tan fácilmente de Dios... ¿De qué Dios?

Una oración litúrgica dice: "Señor, ten misericordia de nosotros que no podemos vivir sin Ti y tampoco vivir contigo".

El rostro divino dejará siempre vértigos de claroscuridad en el alma humana. Es demasiado luminoso y a la vez demasiado oscuro.

No se puede desconocer, ciertamente, que la tentativa de salvar la fe en Comedia es un laberinto intrincado. Ello supone un esfuerzo gigantesco: ir más allá de la megalomanía del Asceta y encender una fe en el Dios de la oscuridad; en el Dios que no abandona su mayestática Otredad; un ser supremo que no pierde su Alteridad primordial.

Se nos habla de un Dios que no interfiere en la contingencia del hombre, aunque se lo interpele con toda la palpitante realidad de Comedia. Con ella estamos a menos de un paso del hundimiento del Dios de las teodiceas y de aquella fe atrincherada en el reduccionismo logocéntrico del dogma.

A propósito de esta tremenda agonía que es Comedia--tragedia en un acto, lo que tal vez cabría esperar en el terreno de la fe sería la presencia de un Dios que simplemente "Sea" y cuya oscura epifanía le permita al hombre serenarse bajo el eco trágico del abismo y el silencio.

En definitiva, sería un Dios para nada, para "nada humano". Volver a la sombra de Dios, de ese "Dios ha muerto", ¿no sería también una vía de reencuentro?

Para la ocasión, destacamos unos versos en donde posiblemente Kazantzakis nos confiesa su fe trágica: 


\section{"Dios habla: \\ Quien me busca, me encuentra. \\ Quien me encuentra, me conoce \\ Quien me conoce, me ama. \\ A quien me ama, amo. \\ A quien amo, destruyo",12}

\section{BIBLIOGRAFÍA}

BIDAL-BAUDIER, M. (1986) N. Kazantzakis, cómo el hombre se hace inmortal. Buenos Aires: Carlos Lohlé.

BIEN, P. (1983) "Introducción” a N. Kazantzakis Buda. Buenos Aires: Carlos Lohlé.

BOYUNGA, A. (1977) "Mithos ke paravolí sto ergo tu Niku Kazantzaki", Diavazo. $\mathrm{N}^{\circ}$ 377. Atenas: Ediciones Diavazo.

CASTILLO DIDIER, M. y QUIROZ, R. (2012) El Maestro Primero, traducción M. Castillo Didier. En Destino y fatalidad en dos dramas juveniles de Kazantzakis. Santiago: Universidad de Chile.

LOM Editores.

CASTILlO DIDIER, M. (2017) El Cristóbal Colón de Kazantzakis. Traducción M. Castillo Didier. Santiago: Universidad de Chile, LOM Editores.

CASTILLO DIDIER, M. (2017) El tiempo, la muerte y la palabra en la\} Odisea de Kazantzakis. Santiago: Universidad de Chile. LOM Editores.

KAZANTZAKIS, N. (1968) Ascesis Salvatores Dei. Introducción Aziz Izzet, Traducción Enrique de Obregón. Barcelona: Editorial Planeta.

KAZANTZAKIS, K. (2012) Comedia - tragedia en un acto. Trad. R. Quiroz. En el vol. Quiroz R. y Castilllo Didier, M.: Destino y fatalidad en dos dramas juveniles de Kazantzakis. Santiago: Universidad de Chile. LOM Editores.

KAZANTZAKIS, N. (2012) El Maestro Primero. Traducción M. Castillo Didier. En el vol. Quiroz, R. y Castillo Didier, M.:

Destino y fatalidad en dos dramas juveniles de Kazantzakis.

KAZANTZAKIS, N. (2013) Odisea. Traducción, estudio y síntesis M. Castillo Didier. Santiago: Tajamar Editores.

12 He aquí un escrito eminentemente de carácter místico musulmán, lo cual es una prueba directa de que Kazantzakis buscaba diferentes fuentes de tradición y que su escuela literaria no se circunscribe al ámbito occidental de la cultura. 
KAZANTZAKIS, N. (1962) Teseo. Traducción Enrique de Juan. Barcelona: Editorial Planeta.

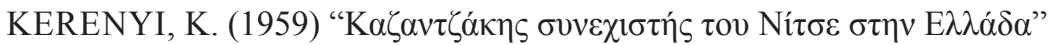
Kazantzakis continuador de Nieztsche en Grecia. Revista Nea Hestía Homenaje a Kazantzakis. Atenas: Ediciones de Hestía.

NÜÑEZ, G. (1997) Kazantzakis. Madrid: Biblioteca Ediciones del Orto

QUIROZ, R. y CASTILLO DIDIER, M. (2012) Comedia - tragedia en un acto. Trad. R. Quiroz. En vol. Destino y fatalidad en dos dramas juveniles de Kazantzakis. Santiago: Centro de Estudios Griegos, Universidad de Chile.

QUIROZ PIZARRO, R. (2003) N. Kazantzakis, dimensiones de un poeta pensador. Santiago: Centro de Estudios griegos, Universidad de Chile. 